\title{
Drug Utilization Evaluation of Anti-Diabetic Medication through Prescription Monitoring
}

\section{Sunaina, Joshi Yogesh*, Singh Ankita}

Department of Pharmacy Practice, School of Pharmaceutical Sciences, Shri Guru Ram Rai University, Dehradun-248001, Uttarakhand, India.

\begin{abstract}
A B S T R A C T
\section{ABSTRACT}

Diabetes is a chronic and potentially disabling disease that represents an important public health and clinical concern. The study was designed to assess the drug utilization evaluation of anti-diabetic medications through prescription monitoring in a tertiary care hospital at capital city Dehradun in a northern state Uttarakhand. Prescriptions from patients of diabetes were selected for the study and data was collected from patients using a questionnaire format. All the necessary and relevant information was collected from out-patient prescriptions, laboratory data reports and also by verbal communication with patients. Out of total 100 prescriptions of diabetic patients, it was found that gender wise distribution of diabetic patients was more in females (64\%) as compared to males (36\%). Among 100 patients, type 1 diabetes occurred in $16 \%$ patients and type 2 diabetes occurred in $84 \%$ patients. It was also analyzed that both type 1 and type 2 diabetes were mostly occurred in females. Among type 2 diabetic patients, Glimepiride were mostly prescribed in $42 \%$ patients, followed by Metformin in $22 \%$ patients and Gliclazide in $20 \%$ while in type 1 diabetes patients, Human Insulin were prescribed in $16 \%$ patients. Prescription analysis showed that maximum prescriptions $(50 \%)$ contain two drugs per prescription while six drugs per prescription were shown by only $2 \%$ prescriptions. This study may provide further help to prescribers for improvement in current prescribing trends in the management of diabetes mellitus.
\end{abstract}

Keywords: Diabètes, Prescription, Drug Utilization, Distribution, Patients.

A R T I C L E I N F 0: Received 08 May 2019; Review Completed 30 May 2019; Accepted 07 June 2019; Available online 15 June 2019

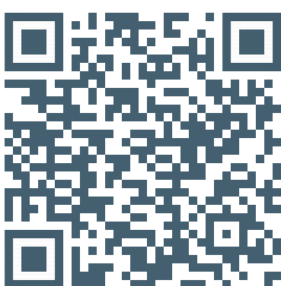

Cite this article as:

Sunaina, Joshi Y, Singh A, Drug Utilization Evaluation Of Anti-Diabetic Medication Through Prescription Monitoring, Asian Journal of Pharmaceutical Research and Development. 2019; 7(3):75-77.

DOI: http://dx.doi.org/10.22270/ajprd.v7i3.537

*Address for Correspondence:

Yogesh Joshi, Department of Pharmacy Practice, School of Pharmaceutical Sciences, Shri Guru Ram Rai University, Dehradun-248001, Uttarakhand, India

\section{INTRODUCTION}

$\mathrm{W}$ orld Health Organization (WHO) defined drug utilization research in 1977 as the marketing, distribution, Prescription and use of drug in a society with special emphasis on the resulting medical, social and economic consequences. The principal aim of the utilization research is to facilitate rational use of drugs in population. For the individual patient rational use of a drug implies the prescription of a well-documented drug in an optimal dose on the right indication, with the correct information and at an affordable price. Drug utilization study is therefore a study designed to describe (quantitatively and qualitatively) the population of users of a given drug (or class of drug) and/or the condition of use (e.g. indication, duration of treatment, dosage, previous or associated treatment and compliance) ${ }^{1-2}$.
Diabetes mellitus (DM) is a group of chronic metabolic disorders characterized by a deficiency of insulin secretion and/or insulin effect, which causes hyperglycemia and is associated with abnormalities in carbohydrate, fat and protein metabolism; and results in chronic complications including microvascular and macrovascular and neuropathic disorders. It is a disease related to the endocrine system and is noted as one of the leading causes of death and disability worldwide. India has the highest number of diabetic patients in the world. It has been estimated that by 2025 , there will be more than 57.2 million cases of diabetes mellitus. Diabetes mellitus can be managed if proper diagnosis, monitoring, medication, diet and exercise are maintained. The management of Type-1 diabetes depends mainly on insulin, whereas the management of Type- 2 diabetes is mainly using oral hypoglycaemic agents ${ }^{3-6}$. 
Diabetes mellitus occurs throughout the world, but is more common (especially type 2) in the more developed countries. The greatest increase in prevalence is, however, occurring in low and middle income countries including in Asia and Africa, where most patients will probably be found by 2030 . The increase in incidence in developing countries follows the trend of urbanization and lifestyle changes, including increasingly sedentary lifestyles, less physically demanding work and the global nutrition transition, marked by increased intake of foods that are high energy-dense but nutrient-poor (often high in sugar and saturated fats, sometimes referred to as the Western pattern diet). The risk of getting type 2 diabetes has been widely found to be associated with lower socio-economic position across countries. The WHO estimates that diabetes resulted in 1.5 million deaths in 2012, making it the 8th leading cause of death. However another 2.2 million deaths worldwide were attributable to high blood glucose and the increased risks of associated complications (e.g. heart disease, stroke, kidney failure), which often result in premature death and are often listed as the underlying cause of death certificates rather than diabetes $^{7-9}$.

Diabetes causes vary depending on your genetic makeup, family history, ethnicity, health and environmental factors. There is no common cause of diabetes that fits every type of diabetic patients. The reason is because the diabetes varies depending on the individual and the type. For instance, the causes of type 1 diabetes vary considerably from the causes of gestational diabetes. Similarly, the causes of type 2 diabetes are distinct from the causes of type 1 diabetes. Insulin was the first treatment for diabetes. It was discovered in 1921, and clinical testing in humans started in 1922. Insulin therapy remains the most effective method of reducing hyperglycemia. Studies have shown that insulin-induced hypoglycemic episodes requiring therapy occur in 1 to 3 per 100,000 patient-years. Weight gain can occur after initiation and is typically about 2 to $4 \mathrm{~kg}^{10,11}$.

\section{MATERIALS \& METHODS}

\section{Study Site:}

The study was performed in Shri Mahant Indiresh Hospital, Dehradun, Uttarakhand, India.

\section{Study Design:}

The study was carried out on those patients, who are following the treatment consisting of anti-diabetic medications in their therapy. Prescriptions from patients of diabetes were selected for the study and data was collected from patients using a questionnaire format.

\section{Source of Data:}

All the necessary and relevant information was collected from:

\section{Out-patient prescriptions}

2. Laboratory data reports

3. Verbal communication with patients

\section{Inclusion Criteria:}

- Out-patients underlying symptoms or diagnosis of any type of diabetes.

- Patients of both gender of any age group.

\section{Exclusion Criteria:}

- Patients admitted to ICU for long term treatment.

- Pregnancy and lactation cases

\section{RESULTS AND DISCUSSION}

\section{Gender-wise distribution of diabetic patients:}

A total of 100 prescriptions of diabetic patients were selectively chosen for the study. While studying about the gender wise distribution of patients, it was found that total number of male patients were 36 accounting for 36 $\%$ of study population, whereas female patient were 64 accounting for $64 \%$ of total study population (Figure 1). Hence, gender wise distribution of diabetic patients was more in females as compared to males.

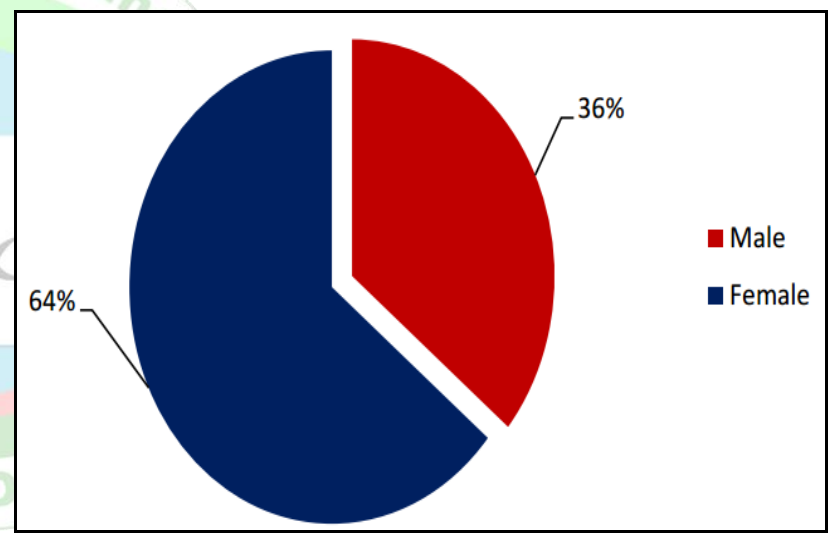

Figure 1: Gender-wise Distribution of Patients

\section{Distribution of Patients According to Type of Diabetes:}

Among 100 patients, both categories of diabetes as type 1 and type 2 were distributed. From study, it was shown that type 2 diabetes were mostly occurred in $84(84 \%)$ patients among which $54(54 \%)$ were females and 30 (30\%) were males. Among type 1 diabetes in $16(16 \%)$ of patients, out of which $10(10 \%)$ were females and $6(6 \%)$ were males as shown in Table 1.

Table 1: Distribution of Patients According to Type of Diabetes

\begin{tabular}{|l|l|l|l|l|}
\hline \multirow{2}{*}{ S. No. } & \multirow{2}{*}{$\begin{array}{l}\text { Categories of Diabetic } \\
\text { Patients }\end{array}$} & \multicolumn{2}{|l|}{ No. of Patients $(\boldsymbol{\%})(\mathbf{n = 1 0 0 )}$} & $\begin{array}{l}\text { Total No. of Patients (\%) } \\
(\mathbf{n = 1 0 0 )}\end{array}$ \\
\cline { 3 - 5 } & & Male & Female & \\
\hline 1. & Type 1 & $06(6 \%)$ & $10(10 \%)$ & $16(16 \%)$ \\
\hline 2. & Type 2 & $30(30 \%)$ & $54(54 \%)$ & $84(84 \%)$ \\
\hline
\end{tabular}




\section{Distribution of Patients According to Drugs Prescribed:}

Out of 100 patients, in type 2 Diabetes Mellitus mostly Glimepiride were prescribed in $42(42 \%)$ patients, followed by Metformin about $22(22 \%)$ patients, then Gliclazide about $20(20 \%)$, and in type 1 Diabetes Mellitus Human Insulin were prescribed in $16(16 \%)$ patients as shown in Figure 2.

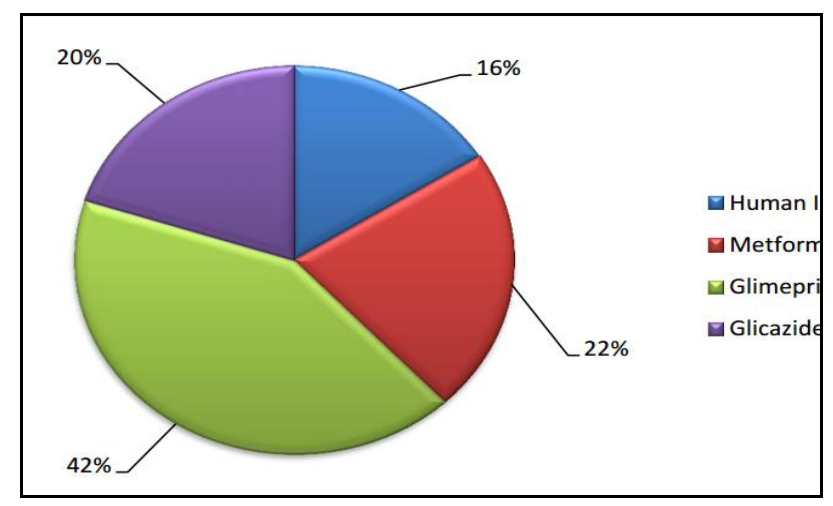

Figure 2: Distribution of Patients According to Drugs Prescribed

\section{Number of Drugs per Prescription:}

Prescription analysis showed that $14 \%$ prescriptions contains one drug per prescription, 50\% prescriptions contains two drugs per prescription, $14 \%$ prescriptions contains three drugs per prescription, $16 \%$ prescriptions contains four drugs per prescription, $4 \%$ prescriptions contains five drugs per prescription and $2 \%$ prescriptions contains six drugs per prescription (Table 2).

Table 2: Number of Drugs per Prescription

\begin{tabular}{|l|l|}
\hline No. of Drugs per Prescription & $\begin{array}{l}\text { No. of Prescription (\%) } \\
(\mathbf{n = 1 0 0 )}\end{array}$ \\
\hline 1 & $14(14 \%)$ \\
\hline 2 & $50(50 \%)$ \\
\hline 3 & $14(14 \%)$ \\
\hline 4 & $16(16 \%)$ \\
\hline 5 & $04(4 \%)$ \\
\hline 6 & $02(2 \%)$ \\
\hline $\mathrm{n}=$ number of prescriptions &
\end{tabular}

\section{CONCLUSION}

Diabetes is a chronic and potentially disabling disease that represents an important public health and clinical concern. The present study was envisaged with the aim of collecting data from diabetes patient population of Dehradun. This study reflected the actual utilization of different anti-diabetic drug classes in diabetes patients. It was observed that among the anti-diabetic drugs, most frequently prescribed drug was Glimepiride followed by Metformin, Gliclazide, and least prescribed drug was Human Insulin in monotherapy. Surprisingly, none of the prescriptions were in accordance to the $\mathrm{WHO}$ / American Diabetic Association (ADA) guidelines for the utilization of anti-diabetics as a monotherapy. It is needless to mention that such guidelines are aimed to achieve a cost effective therapy and for choosing treatment alternatives. Physicians should follow such guidelines so as to attain therapeutic goals. Patient counseling needs to be encouraged to overcome the ever-rising problem of noncompliance in diabetes mellitus patients. It is hoped that the present study help prescribers to further improve the current prescribing trends in the management of diabetes mellitus.

\section{REFERENCES}

1. Introduction to Drug Utilization Research. WHO, 2003.

2. WHO Expert Committee. The Selection of Essential Drug, Technical Report Series No. 615. Geneva: World Health Organization. 1977.

3. Dipiro JT, Talbert RL, Yee GC, Matzke GR, Wells BG, Posey LM. Pharmacotherapy: a pathophysiologic approach. Sixth edition pp no. $1333-1367$.

4. Joshi Y, Pant R, Mittal P, Juyal V, Agrawal AC. Prevalence of Diabetes Mellitus in Patient Population of Dehradun. The Pharma Review. 2008; 6(33):168-170.

5. Joshi Y, Pant R, Rawat M. Evaluation of Drug Utilization Pattern of Antidiabetic Drugs among Patients of Dehradun. The Indian Pharmacis. 2008; 7(72):65-70.

6. Adhikari AK, Vidyasagar G, Rathore DS, Balaram G, Bhakti G. A drug utilisation review on antidiabetic drugs in a tertiary care hospital of india, Indian journal of hospital pharmacy 2011

7. Maniyar Y, Bhixavatimath P, Akkone V. A Drug Utilization Study in the Ophthalmology Department of a Medical College, Karnataka, India. Journal of Clinical and Diagnostic Research. 2011; 5(1):82-84.

8. Holloway K, Green T. Drug and therapeutics committees - A practical guide. Geneva: World Health Organization. 2003; 71-94.

9. Meigs JB, Cupples LA, Wilson PW. Parentral Transmission of Type 2 Diabetes: The Framingham Offspring Study. Diabetes care 2000; 49: 2201-2207.

10. American Diabetes Association. Standards of Medical Care in Diabetes - 2015. Diabetes Care. 2015; 38(1):S33-S40.

11. Rodbard HW, Blonde L, Braithwaite SS. AACE Diabetes Mellitus Clinical Practice Guidelines Task Force. American Association of Clinical Endocrinologists Medical Guidelines for Clinical Practice for the Management of Diabetes Mellitus. Endocr Pract. 2007; 13(1):1-68. 